\title{
İslam'da Kadın ve Cinsiyet Tartışmalarına Tarihselci Bir Bakış Women \& Gender Issues in Islam From a Historicist Perspective
}

Arş. Gör. Hacer Yetkin ${ }^{1}$

Son yıllarda Kur'ân'ın anlaşılmasına yönelik yayınları ve tarihselci olarak nitelenebilecek yaklaşımı ile dikkat çeken Çukurova Üniversitesi İlahiyat Fakültesi Tefsir Profesörü Mustafa Öztürk'ün "Cahiliyeden İslâmiyet'e Kadın” isimli eseri, yazarın kadın ve toplumsal cinsiyet konularında çeşitli kongrelerde ve ilmî toplantılarda sunduğu tebliğlerin bir araya getirilmesinden oluşmaktadır. Eser bu sebeple belli bir amaca yönelik bütüncül bir sistematikten yoksundur ve yazarın da girişte ifade ettiği üzere bazı konularda tekrarlar barındırmaktadır.

Mustafa Öztürk'ün Kur'ân'ın kadın konusundaki söylemine ilişkin görüşleri, Kur'ân'a bakışındaki genel prensipler bağlamında değerlendirilmelidir. Öztürk, Kur'ân'ı bugünün insanı olarak doğru şekilde anlayabilmek için, Kur'ân'ın bütününün değer nitelikli normatif hükümlerden oluşmadığını; çağlar üstü, evrensel bir nitelik taşımadığını kabul etmek gerektiğini savunur. Öztürk'e göre Kur'ân'ın temel inanç ve ahlâk normları değer içerikliyken toplumsal düzen ve hukukla ilgili hükümleri büyük ölçüde durumsal ve olgusal niteliklidir. Değer içerikli hükümler toplumdan topluma, dönemden döneme değişmeyen ve bütün peygamberlerin sunduğu ortak mesajları içerir. Olgusal hükümler ise şeriat olarak nitelenen, her peygamberin kendi dönemine ve toplumuna göre farklılaşabilen, altıncı yüzyıl Arap örfünün genel karakteristiği ile iç içe geçmiş hükümlerdir.

Öztürk'ün tespitine göre, bugünün Müslümanlarının Kur'ân'ın bu hükümlerine bakışlarında iki eğilim göze çarpmaktadır. Zahirî anlayışa benzer bir bakış açısını benimseyenler, Kur'ân'ın bütün hükümlerinin değer içerikli olduğuna ve lafız-mana bütünlügü içerisinde nasıl anlaşılıyorsa her dönemde ve her toplumda öylece uygu-

1 Marmara Üniversitesi, İlahiyat Fakültesi, İslâm Hukuku Ana Bilim Dalı Altunizade Üsküdar. Eposta: hkontbay@yahoo.com 
lanması gerektiğine inanmakta; modernizmin tazyiki ve travması altında kalan modernist yaklaşıma sahip olanlar ise Kur'ân'daki bazı hükümleri ilk bakışta bugünün insanının değer yargıları açısından kabul edilemez bulduklarından tefsir-te'vil kurallarının sınırlarını aşmak pahasına ayetleri modern dönem anlayışına uygun şekilde yeniden ifade etmeye çalışmaktadırlar. Mustafa Öztürk, her ikisini de isabetsiz bulduğu bu iki eğilime karşı1lık, Kur'ân'ın anlaşılmasında, onun indiği toplumun olgusallığının dikkate alınmasını esas kabul eden, tarihselcilik olarak nitelenebilecek bir yaklaşım önerir. Buna göre çoğunlukla Mekke döneminde inen değer içerikli ayetler İslâm'ın değişmez prensipleri olarak kabul edilecek; daha çok Medine döneminde gönderilen, indiği toplumun yapısını verili olarak kabul edip bu olgusallığın üzerinde şekillenen hükümler ise tarihsel bağlamı içinde anlaşılacaktır. Öztürk'e göre bu yöntem hem Kur'ân'ın kendi anlayışı, hem de ilk dönemde sahabenin Kur'ân'a yaklaş1mı ile uyumludur. Kur'ân'ın Arapça olduğunu vurgulayan ayetler, Kur'ân vahyinin indiği topluma doğrudan hitap edebilmesi için Arap değer dünyasına ve anlayış biçimine uygun olarak gönderildiğine işaret etmektedir. Kur'ân'da nesih olgusunun ilk dönemlerden itibaren kabul edilmesi ve bazı ayetlerin anlaşılmasında sahabenin "bu ayetlerin indiği şartların artık mevcut olmadığı için uygulama imkânı kalmadığını" belirtmeleri de Kur'ân'ın tarihsel bağlam içinde okunması gerektiğine delil teşkil eder. Öztürk, bu bakış açısının; cariyelerin durumu, ceza ve miras hukuku gibi bugünün Müslümanının benimsemekte ve savunmakta zorlandığı ayetlerin anlaşılmasında ortaya çıkan sorunları büyük oranda çözeceğini düşünmektedir.

Öztürk'ün, Kur'ân'ın anlaşılmasında bir problem olarak gördüğü hususlardan birisi de İslam'ın indiği toplumda bir devrim yaparak yepyeni bir dünya kurduğu, cahiliye olarak nitelenen dönemden İslam'a geçişte hiçbir şeyin eskisi gibi kalmadığ 1 düşüncesidir. Öztürk'e göre İslam, Arap örfünden gelen pek çok uygulamayı olduğu gibi kabul etmiş, İslam'ın evrensel normları ile çelişen bazı hususları da tamamen kaldırmış ya da ıslah etmiştir. Dolayısıyla Kur'ân, bugünkü İslam şeriatındaki hükümlerin birçoğunu ibtidaen kendisi koymamış, var olan uygulamaları kabul ederek düzenlemiştir. Bu bağlamda İslam'ın örfe/ma'rufa geniş bir alan bıraktığı söylenebilir. Kur'ân'da çeşitli düzenlemelerle ilgili birkaç yerde geçen ma'ruf kelimesi; insan aklında ve vicdanında kabul görüp benimsenen, rıza gösterilen, nahoş olarak değerlendirilmeyen örfü/geleneği ifade eder. Kur'ân'da bazı hususların ma'rufa göre belirlenmesi ve uygulanmasının salık verilmesi, o dönemin anlayışı ve sağduyusu ile şekillenen uygulamanın, o dönem insanı için geçerli kabul edildiği anlamına gelir. Öztürk'e göre cahiliye olarak nitelediği toplumun ma'rufunu dikkate alan İslam'ın, toplumsal bazı düzenlemeleri her devrin Müslümanının ma'rufuna havale ettiğini düşünmek mümkündür ve bu kabul, bugünün Müslümanının Kur'ân'ın evrensel değerleri ile birlikte, on dört asırlık birikimini esas alarak kendi ma'rufunu oluşturması ihtiyacını da beraberinde getirir. 
Mustafa Öztürk'ün İslam'da kadının konumu hakkındaki bakış açısı, burada özetlediğimiz ve kendisinin de eserinde sıkı bir şekilde muhafaza ettiği, Kur'ân'ın tarihselliğine dair genel çerçeve içerisinde değerlendirilmelidir. Kadın konusu beş bölümden oluşan eserin ilk iki bölümünde tahlilî olmaktan ziyade tasvirî nitelikte ele alınmışken diğer üç bölüm daha kuşatıcı bir bakış açısına sahiptir.

Birinci bölümde İslâm öncesi Arap toplumunda kadının konumu; şahıs hukuku, nikâh, talak ve miras konuları bağlamında ayrı ayrı ele alınmıştır. Yazarın tespitine göre İslam'dan önce de İslami dönemde olduğu gibi nikâh akdi, mehir, nikâh velayeti, nikâh merasimi, velime uygulamaları mevcuttu. Ancak İslam, İslam'ın toplum tasavvuru ile uyuşmayan, özellikle kadının mağduriyetine sebep olan (mut'a, şiğar, makt gibi) bazı nikâh türlerini yasaklamıştır. Öztürk bu bölümde Kur'ân'ın, indiği toplumun bu konulardaki örfüne gerekmedikçe müdahale etmediğini, İslam'ın özüne tamamen ters konuları kaldırıp bazı ayrıntılarda iyileştirme yoluna gittiğini, bu anlamda toplumun benimsemekte zorlanacağ bir devrimden ziyade tedrîcî bir geçiş sürecinin esas alındığını, toplumsal gerçekliğin göz önünde bulundurulduğu, realist bir yaklaşımın benimsendiğini vurgulamaktadır.

İkinci bölümde yazar, klasik tefsir literatüründeki kadın imgesini çeşitli tefsir eserleri ve çeşitli ayetlerin tefsirleri üzerinden başarılı bir biçimde tasvir eder. Bu doğrultuda, klasik tefsirlerde çeşitli ayetler bağlamında dile getirilen; kadının zayıf ve noksan yaratıldığı, bu yüzden erkeğe tabi olduğu, kadının erkek için dünya hayatında yaratılan nimetlerden biri olduğu, erkeğin kadından bir derece daha üstün olduğu, bu yüzden şahitliğinin kabul edilmediği ve mirastan yarım pay aldığı gibi görüşleri aktarır. Öztürk’ün tespitine göre, klasik tefsirlerdeki kadın imgesi, hemen hemen her açıdan, Judeo-Christian kültürdeki kadın telakkisi ile örtüşmektedir. Bu telakkide var olan, kadının ataerkil toplumda şekillenen sosyal statüsü, fitne unsuru oluşu, çocuk doğurmasının önemi ve annelikle birlikte saygın bir konuma yükselmesi gibi hususlar, klasik tefsirlerdeki yorumlarda da mevcuttur. Nitekim kadının yaratılışı ve Hz. Âdem ve Havva'nın cennetten çıkarılışı hakkında Kur'ân'da yer almayan detaylar, tefsirlerde İsrâilî kaynaklardan aktarılan rivayetlerle anlatılmıştır. Bu hususlarla ilgili olarak yazarın bir tespiti de ilk dönem tefsirlerine göre sonraki tefsirlerde kadın imgesi ile ilgili bu ve benzeri vurguların nispeten arttı̆̆ıdır. Bu noktada Öztürk'ün, erkeğin en fazla dört kadınla evlenebileceği şeklinde yorumlanan Nisa Suresi 3. ayetinin (mesnâ ve sülâse ve ruba'a) çok eşlilikle ilgili bir sınırlama getirmediği, çok eşliliğin sayısal limitini düzenleyen bir hukuki hüküm içermediği, söz konusu sınırın icmâ ile sabit olduğu; dolayısıyla zikredilen ayetin eşler arasında adaletli davranılamayacağını vurgulayan ayetle birlikte değerlendirilerek İslam'ın tek eşliliği esas aldığ rumlanmasının da isabetli olmadığı şeklindeki görüşü dikkate değerdir (s. 124-125). 
“Kur'ân'da Karı-Koca Hakları” başlığını taşıyan üçüncü bölümde yazar, hak kavramının olumsuz çağrışımlarına ve modern dönemde ezilen kitlelerin reaksiyoner hareketleri ile şekillenen hak arayışının tezahürlerine değinir ve hak kavramından ziyade sorumluluk bilincinin vurgulanmasının önemine dikkat çeker. Yazara göre eşlerin birbirine karşı doğal hukuka dayalı hakları ve sorumlulukları olduğu gibi toplumsal vasatta temellenen pozitif hukuka dayalı sorumlulukları da bulunmaktadır. Evliliğin sevgi ve saygı çerçevesinde yürütülmesi gibi ahlaki-insani değerler birinci gruba girer. İkinci gruptaki haklar ve sorumluluklar kapsamına erkeğin haklarının/sorumluluğunun kadından bir derece fazla olduğunu dile getiren ayet (Bakara 2/228) ile erkeğin kadın üzerinde "kavvam" olduğunu ifade edip erkeğin kadını tedip hakkından bahseden (Nîsâ 4/34) ayetler üzerinde durulur. Bilhassa sonuncu ayetin günümüz insanı açısından izahının zor olmasından dolayı savunmacı bazı yorumlara gidildiğine dikkat çekilir. Yazara göre bu yorumlara sevk eden hata, Kur'ân'1 kendi özgün bağlamı ve kendi tarihselliği içinde okuyup anlamaktan kaçınılmasıdır; zira boşanmayı tek makul çözüm kılacak derecede şiddetli geçimsizlik hâlinde dahi eşlere geçmişteki güzel günlerin hatırasına uygun davranmalarını salık veren Kur'ân'ın, kıyamete kadar tüm Müslüman erkeklere karılarını dövme talimatı verdiği düşünülemez. Bu bölümde yazarın dikkat çektiği diğer bir husus da karı-koca arasındaki haklar ve sorumluluklar bağlamında değerlendirilebilecek ayetlerin çoğunlukla boşanma konusu ile ilgili olmasıdır. Buradan anlaşılan şudur: Kur'ân, normal yürüyen bir evliliğin haklarını ve sorumluluklarını düzenleme gereği duymamış ve bunları örfe/ma'rufa bırakmıştır. Boşama ile ilgili belli kuralların zikredilmesi ise boşama ile kadının mağdur edilmesini önlemeye yöneliktir.

Yazar, "Kur'ân Bağlamında Toplumsal Cinsiyet ve Kadın” başlığını taşıyan dördüncü bölümde, toplumsal cinsiyet tartışmalarında İslâm dünyasında bir ifrat ve tefrit durumunun göze çarptığını; bazıları tek tek sorunlardan ziyade bizzat kadını bir sorun olarak görürken muhafazakârlığı ile öne çıkan ve her yeni yoruma şüphe ile yaklaşan diğer grubun ise İslam'da kadına dair bir sorunun varlığını tümden reddettiğini söyler. Buna mukabil, yazara göre, İslâm tarihini bir yanlış yorumlar tarihi olarak gören ve keskin bir söylem benimseyen İslamcı feminizm de modern zamanlara özgü ve aynı ölçüde sorunludur. Toplumsal cinsiyet bağlamında Kur'ân naslarını inceleyen Öztürk, değersel-durumsal beyanları birbirinden ayırır. Kur'ân'ın toplumsal cinsiyetle ilgili değersel beyanının en açık örneği, Kur'ân'da kadınlardan çok fazla söz edilmediğinden şikâyet eden Ümmü Seleme'nin bu sözü üzerine nazil olan ayettir: “Allah'a yürekten teslim olmuş erkekler ve kadınlar, gerçek manada iman etmiş erkekler ve kadınlar, Allah'a verdikleri itaat sözüne sadakat gösteren erkekler ve kadınlar, Allah yolunda karşılaştıkları sıkıntı ve zorluklara göğ̈̈s geren erkekler ve kadınlar, Allah’a derin saygı ve bağlılık gösteren erkekler ve kadınlar, Allah yolunda mallarını harcayan erkekler ve kadınlar, oruç tutan erkekler ve kadınlar, iffetlerini koruyan erkekler ve kadınlar, Allah'1 çokça anan erkekler ve kadınlar var ya, işte Allah onlara mağfiret edecek ve çok büyük bir mükafat verecektir.” (Ahzâb 33/35). Bu ayet, ontolojik anlamda ve kulluk/ 
mükellefiyet açısından kadınla erkek arasında bir fark gözetilmediğinin delilidir. Öztürk yine değer içerikli ayetler olarak kadın ve erkek Müslümanların birbirlerinin velisi olduğunu ifade eden ayeti (Tevbe 9/71) ve erkekle kadının birbirinin elbisesi olduğunu ifade eden ayeti (Bakara 2/187) zikreder. Günümüzde tartışma konusu olan çok eşlilik, kadının şahitliği, miras payı gibi konulara ilişkin Kur'ânî beyanları ise durumsal/tarihsel hükümlere örnek olarak dile getirir. Sonuç olarak yazara göre Kur'ân, toplumsal düzene iliş̧kin konularda reel ve işlevsel bir tutum benimsemiş; erkek-kadın ilişkisi konusundaki toplumsal teamüllere çok fazla müdahale etmemiştir. Bu noktada Kur'ân'ın kadınla erkeği toplumsal statü bakımından eşitlemeye çalıştığı söylenemez. Kur'ân, aradaki eşitsizliğe müdahale etmemiş fakat bu toplumsal vasat içerisinde adaleti ve hakkaniyeti tesis etmeyi hedeflemiştir.

Kitabın "Kur'ân Çerçevesinde Toplumsal Cinsiyet Meselelerine Çözüm Önerileri” başlığını taşıyan son bölümünde yazar, genel itibarıyla çözümlerden bahsetmekten ziyade, başlangıçta özetlediğimiz üzere, Kur'ân'ın, değersel-durumsal ayrımı ekseninde nasıl okunması gerektiğine yönelik görüşlerini dile getirir. Bu açıdan bu bölümün eserin son değil ilk bölümü olarak düzenlenmesi daha isabetli olabilirdi. $\mathrm{Bu}$ bölümde yazar, Seyyid Kutub'un örnekliğinde, modern dönemin sorunlarına İslam adına çözüm bulmayı reddeden ve sorunları çözmek yerine toplumu tümden değiştirmeyi savunan yaklaşımı gerçekçi bulmayarak eleştirir. Öztürk’ün çözüm önerisi genel itibarıla toplumsal cinsiyete dair ayetlerin tek tek ele alınması yerine tüm ayetlerin muhteva açısından bir değerler hiyerarşisi içerisinde tasnif edilmesidir. Yazar, vahyin ilahî irade ile beşerî ve tarihî vakıa arasında diyalektik bir süreç olarak algılanması gerektiğini, dolayısıyla Kur'ân'ın insana rağmen insan için çözümler getirmediğini, bazı ayetlerin evrensel olmasına karşılık bazı ayetlerin bağlamsal olduğunu ve her ayetin aynı hüküm değerini taşımadığını savunur. Bunun yanında Öztürk’e göre, Kur'ân'ın Arap örfündeki pek çok uygulamayı ibkâ etmesi, bu uygulamaların tarih üstü, evrensel nitelik taşıması sebebiyle değil, o dönem Araplarının toplum yapısına ve maslahatlarına uygun olmasından dolayıdır. Bu bağlamda yazar, ayetlerin yorumu konusunda gözlemlenen metodolojik bir tutarsızlığa da dikkat çeker. Meselâ Kur'ân'da at beslemeyi emreden ayet, nükleer silah üretimini temellendirecek kadar ileri yorumlara tabi tutulurken kadının şahitliği konusunda olgusallık dikkate alınmamakta ve ayetin o hâliyle uygulanmasında israr edilmektedir.

Mustafa Öztürk, Kur'ân'ın anlaşılması konusundaki ufuk açıcı bakış açısı dışında, kadın meselesine özel bir yorum ya da somut bir çözüm önerisi sunmamaktadır. Görünüşe göre kadın konusu, yazarın gündemini özel olarak işgal eden bir mesele değildir. Nitekim Öztürk'e göre İslam'ın, bugün kadın konusunda görüş beyan edenlerin tasavvur ettiği şekilde bir "kadın meselesi" yoktur. Kadın konusu, modern dönem travmalarının etkisi ile “İslam'ın yumuşak karnı” hâline gelmiştir. Kur'ân'ın değer nitelikli ayetleri, ontolojik anlamda kadınla erkek arasında hiyerarşik bir ilişki kurmaz. Olgusal ayetler ise kadın ve aile 
meselelerini sıfirdan kurgulamak ve prensip hükümleri vaz etmekten ziyade dönemin Arap örfünü dikkate alan bir yaklaşımla ve sorun ortaya çıkan alanlara yoğunlaşarak hüküm getirmiştir. Dolayısıyla yazarın Kur'ân'ın bilhassa hukuki düzene ilişkin ayetlerinin evrensel değil tarihsel nitelikli olduğu yönündeki genel yaklaşımı, kadının toplumsal konumunu düzenleyen ayetler için de geçerlidir. Bu açıdan çok vurgulu dile getirilmiş olmamakla birlikte, nikâhın resmî tescili ve talâkın mahkeme sürecine bağlanması gibi somut bazı çözüm önerilerinin eserde dile getirildiği, ancak genel itibarıla spesifik hukuki konuların incelenmediği söylenebilir. Bununla birlikte, eserin tarihselci bakış açısının kadın meselesini nasıl ele aldığını gösteren bir metin olarak literatüre katkısı kayda değerdir.

Kur'ân tefsirinde tarihselci yaklaşım, ana akım tefsir geleneği tarafından hâlen genel bir kabule mazhar olmamıştır. Dolayısıyla, tarihselci yaklaşım hakkında dile getirilen çekinceler ve eleştiriler, Öztürk'ün bu yazıya konu olan eseri için de söz konusu edilebilir. Bilhassa İslam'ın toplumsal işleyiş açısından devrim sayılabilecek bir yenilik getirmediği fikri ve bu bağlamda ma'ruf kavramına biçilen merkezî rol, İslam'ın şekillendirmediği ma'rufun belirlenmesinde neyin esas alınacağı sorusunu akla getirir. Yazar, Kur'ân'ın Arap örfünü pek çok noktada ibka ettiğini ve devrimsel değil tedrîcî bir değişimi öngördüğünü, bu sebeple de toplumsal ilişkilere önemli ölçüde müdahale etmeyerek bu ilişkilerin düzenlenmesinde ma'rufun esas alınmasını kabul ettiğini savunur ve buradan yola çıkarak bugünün Müslümanının sağduyusuyla kendi ma'rufunu ortaya koyabileceğini söyler. Ancak ma'rufun belli esaslara bağlı olmaksızın sadece insanların ortak/yaygın kabulüne göre belirlenmesi, her zaman istenilen sonucu vermeyebilir. Zira toplumun ortak kabulleri her zaman ideal adalete ve hakkaniyete göre şekillenmeyebilir ve bizzat örfün kendisi dezavantajlı grupları ortaya çıkarabilir. Kadın konusu bağlamında düşünüldüğünde de ma'rufun yüzyıllardır süren kabulleri devam ettirerek kadının tarih boyu ikinci planda kalmasına sebep olan süreci pekiştirebileceği göz ardı edilmemelidir. Nitekim günümüzde kadın hakları savunucularının kadının toplumda geri planda kalmasına sebep olan faktörlere karşı mücadeleleri, büyük oranda bunu destekleyen ataerkil gelenekle mücadeleyi içermektedir. Yazarın savunduğu üzere nüzul dönemi toplumsal vasatını esas alan ve bu sebeple kadının toplumsal konumunu çok fazla değiştirmeyen Kur'ân naslarının yanında, hâlihazırdaki geleneklerin de erkeğin üstünlüğünü perçinlemesi karşısında Müslümanların güncel ma'rufunun kadın haklarını koruyacak tarzda şekillenmesi için -yazarın eleştirdiği modern meydan okuma dişında- bir motivasyon yok gibi görünmektedir. Bu sebeple, ma'rufun belirlenmesinde sadece insanların genel hüsnükabulünün yeterli olmadığını, İslam'ın temel hedeflerinden olan adaletin ve maslahatın gerçekleşmesini sağlayacak ma'rufun ortaya konulabilmesi için daha kuşatıcı esaslara ihtiyaç olduğunu ifade etmek gerekir. 